\title{
REVIEW
}

\section{Clinical review: Anticoagulation for continuous renal replacement therapy - heparin or citrate?}

\author{
Heleen M Oudemans-van Straaten ${ }^{1 *}$, John A Kellum² and Rinaldo Bellomo ${ }^{3}$
}

\begin{abstract}
Heparin is the most commonly prescribed anticoagulant for continuous renal replacement therapy. There is, however, increasing evidence questioning its safety, particularly in the critically ill. Heparin mainly confers its anticoagulant effect by binding to antithrombin. Heparin binds to numerous other proteins and cells as well, however, compromising its efficacy and safety. Owing to antithrombin consumption and degradation, and to the binding of heparin to acute phase proteins, and to apoptotic and necrotic cells, critical illness confers heparin resistance. The nonspecific binding of heparin further leads to an unpredictable interference with inflammation pathways, microcirculation and phagocytotic clearance of dead cells, with possible deleterious consequences for patients with sepsis and systemic inflammation. Regional anticoagulation with citrate does not increase the patient's risk of bleeding. The benefits of citrate further include a longer or similar circuit life, and possibly better patient and kidney survival. This needs to be confirmed in larger randomized controlled multicenter trials. The use of citrate might be associated with less inflammation and has useful bio-energetic implications. Citrate can, however, with inadequate use cause metabolic derangements. Full advantages of citrate can only be realized if its risks are well controlled. These observations suggest a greater role for citrate.
\end{abstract}

\section{Introduction}

Heparin is the most commonly prescribed anticoagulant for use during continuous renal replacement therapy (CRRT) [1]. By implication, it is considered the standard of care. There is, however, increasing evidence questioning the safety of heparin particularly in the critically ill, and

*Correspondence: hmoudemans@gmail.com

'Department of Intensive Care Medicine, Onze Lieve Vrouwe Gasthuis, Oosterpark

9, 1091 AC Amsterdam, The Netherlands

Full list of author information is available at the end of the article there are accumulating data on a potential better alternative, regional anticoagulation with citrate. In the present review, we discuss some of the complex interactions between heparin and the coagulation and inflammation pathways, the associated consequences of such interactions in terms of efficacy and safety in the critically ill, and the availability of the promising alternative citrate.

\section{Heparin}

In the present manuscript we often refer to heparin, not discriminating between unfractionated heparin and low molecular weight heparin (LMWH). Clinicians should, however, be aware of their differences [2]. LMWHs have a lower antithrombin (AT) dependency, cause less tissue plasminogen activator inhibitor depletion, exhibit less binding to proteins and cells, cause less activation of platelet factor 4 and cause less heparin-induced thrombocytopenia. Some of the effects mentioned below will therefore be less pronounced for LMWH. Many of these effects are, however, described for LMWH as well - in such cases, we have indicated this in the text or the tables.

\section{Heparin resistance}

\section{Low antithrombin due to consumption and inactivation}

The anticoagulant effect of heparins depends on potentiating AT, the most important endogenous inhibitor of thrombin and other coagulation factors [2]. In critically ill patients, however, AT concentrations are often reduced as a result of consumption due to activation of coagulation in conditions such as sepsis or systemic inflammation. AT is also reduced as a result of proteolytic degradation by granulocyte-derived elastase, and this effect is actually enhanced by heparin [3,4]. During inflammation, elastase release is increased while its inactivation is decreased, because oxygen radicals decrease the activity of its natural inactivator $\alpha_{1}$-antitrypsin. Both high AT consumption and increased AT degradation thus contribute to heparin resistance during critical illness.

\section{Critical illness-induced heparin binding}

Heparins not only bind to AT, but additionally to numerous other proteins and cells, thereby inducing unpredictable effects on many body functions. The binding of heparin 
to proteins other than AT limits the amount of heparin available to act as a cofactor for AT and thus decreases its anticoagulant effect [5]. So-called heparin-binding proteins are released from endothelial stores [6]. Among these are acute-phase reactants such as platelet factor 4, histidine-rich glycoprotein, vitronectin, fibronectin and lipopolysaccharide-binding protein, all of which increase in sepsis and other forms of inflammation [2,7-9]. Furthermore, heparin avidly binds to apoptotic and necrotic cells to discrete domains released from the nucleus onto the membrane as the cell dies [10]. Affinity of dead cells decreases if heparins with a lower molecular weight are used. Apoptosis is a key mechanism of cell injury in sepsis-related multiorgan failure, while necrotic cells are abundant in ischemia reperfusion injury. Importantly, the heparin-binding sites on apoptotic cells also signal phagocytotic clearance, and thus heparin may actually delay such clearance [10].

A recent study in critically ill patients with acute kidney injury receiving CRRT with LMWH anticoagulation (nadroparin) found that early filter clotting was associated with severe organ failure, consumptive coagulopathy and heparin resistance. LMWH resistance was independent of low AT levels [11]. In addition to low AT levels, increased heparin binding is therefore a feature of critical illness, also with the use of $\mathrm{LMWH}$, and contributes to heparin resistance and possibly to other deleterious effects such as delayed phagocytotic removal of dead cells [10].

\section{Heparin and bleeding}

The main drawback of heparin is that it causes systemic anticoagulation in addition to circuit anticoagulation. Heparin thus increases the patient's risk of bleeding. Critically ill patients are at risk of bleeding due to recent surgery, trauma, mucosal lesions and coagulopathy. More or less severe bleeding events are reported in 10 to $50 \%$ of cases, depending on the population and the degree of anticoagulation $[12,13]$. Using no anticoagulation treatment is a safe option with regard to bleeding, but not to clotting, because the circuit life is generally reduced. Circuit anticoagulation without systemic anticoagulation (for example, regional anticoagulation) represents an ideal solution. Antagonizing heparin by administering protamine after the filter confers regional anticoagulation. The circulating heparin-protamine complexes, however, may be harmful [14]. Regional anticoagulation with sodium citrate seems an attractive alternative. This topic is discussed below.

\section{Heparins and inflammation \\ Proinflammatory effects: antithrombin mediated}

Binding of heparin to AT not only potentiates its anticoagulant effects, but additionally inhibits the anti-inflammatory actions of AT. The anti-inflammatory effects of AT are exerted through binding to glucosaminoglycans on endothelial membranes, enhancing the formation of prostacyclin. The binding of AT to glucosaminoglycans diminishes the adherence and migration of leukocytes, reduces platelet aggregation and decreases proinflammatory cytokine production $[15,16]$. Heparin binding to AT abolishes this effect [15]. Furthermore, during sepsis or ischemia reperfusion, elastase is increased. Recent data indicate that heparin, which normally potentiates AT, inactivates AT in the presence of elastase. This process leads to proinflammatory and procoagulant effects on the endothelium in sepsis, which may compromise the microcirculation and threaten tissue perfusion [4]. Heparin may thus have adverse effects on the microcirculation in sepsis $[17,18]$.

\section{Proinflammatory and anti-inflammatory effects not related to antithrombin}

Both unfractionated heparin and LMWH can mobilize inflammatory mediators - such as myeloperoxidase, lactoferrin, elastase and platelet factor $4-$ not only from circulating neutrophils and platelets and from cells adhered to and activated by the dialysis membrane, but also from glucosaminoglycans such as heparan sulfate on the endothelial surface [19-21]. Although this release may be interpreted as being protective for the endothelium, LMWH dialysis has been associated with higher serum concentrations of oxidized low-density lipoproteins compared with citrate dialysis, possibly indicating systemic oxidizing effects by myeloperoxidase [20].

Mobilization of inflammatory mediators from endothelial glucosaminoglycans may be especially relevant in sepsis and other forms of inflammation. Heparin also releases the protective superoxide dismutase from the endothelium [22] and may have other anti-inflammatory properties as well [23]. These anti-inflammatory properties may be partially mediated by inhibiting thrombin generation [24]. In addition, heparin - at much higher doses than used for anticoagulation - seems to attenuate endothelial dysfunction after ischemia-reperfusion injury by blocking the inflammatory cascade at multiple levels, including complement activation [25], P-selectin and L-selectin-initiated cell adhesion and influx, and activation of the proinflammatory transcription factor NF- $\mathrm{KB}$ $[26,27]$. In contrast to the observations in plasma-free conditions, where heparin seems to reduce endotoxininduced cytokine synthesis dose dependently [9] and to bind TNF [23,28], both unfractionated heparin and LMWH cause a dose-dependent increase in IL- 8 and IL-1 $\beta$ in plasma, which depends on the presence of lipopolysaccharide-binding protein [9]. Heparin binds to lipopolysaccharide-binding protein, and this binding facilitates the transfer of lipopolysaccharide to the CD14 receptor, thereby augmenting the endotoxin-induced activation of monocytes $[9,18]$. It should be noted that, 


\section{Heparins and inflammation}

$\mathrm{H} \gg \mathrm{AT}>\longrightarrow$ thrombin generation $\downarrow$
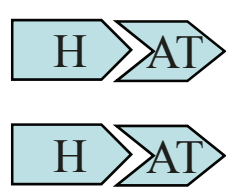

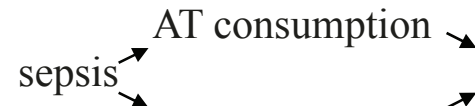

heparin resistance

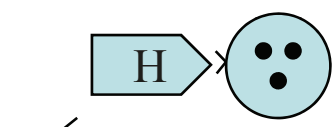

necrotic \& apoptotic cells

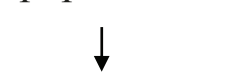

delayed phagocytosis

H $>$ acute phase proteins

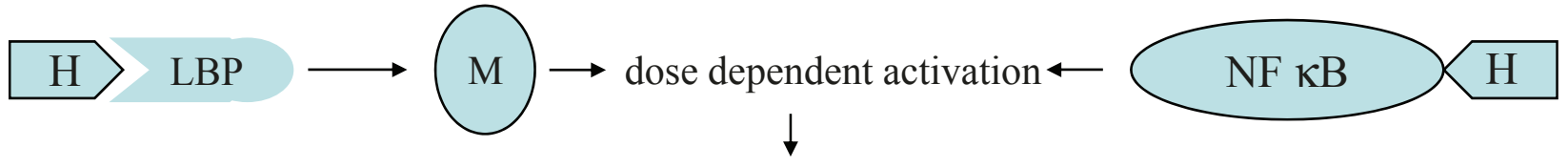

pro-inflammatory cytokines $\uparrow \downarrow$

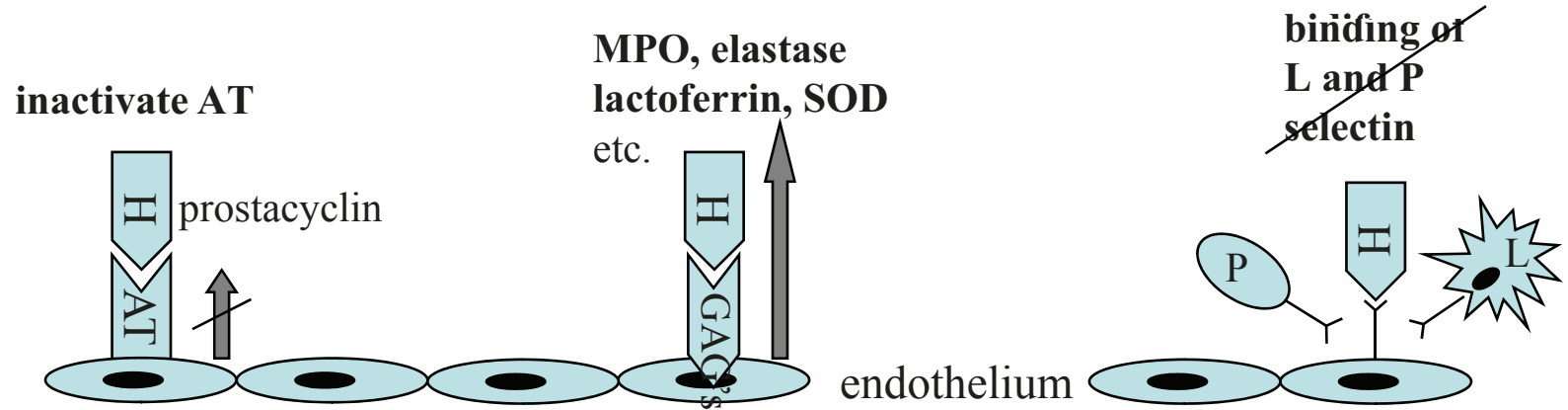

Figure 1. Simplification of heparin binding to proteins and cells. Heparins bind to proteins and cells, and thereby interfere with the inflammatory cascade and, altogether, confer unpredictable consequences for critically ill patients. H, heparin; AT, antithrombin; LBP, lipopolysaccharide-binding protein; M, monocyte; MPO, myeloperoxidase; SOD, superoxide dismutase; GAGs, glucosaminoglycans; P, platelet; L, leukocyte.

for the prevention of clotting of the extracorporeal circuit, higher doses of heparins are often required, increasing the risk of proinflammatory effects [9,29].

Altogether, translation of these experimental results to critically ill patients remains speculative. Post hoc analysis of the major sepsis trials in humans suggests that lowdose heparin might have favorable effects on survival [23]. There is, however, probably a bias - the patients receiving heparin were less critically ill compared with those judged unable to tolerate heparin. Altogether, due to its avid binding properties, both unfractionated heparin and LMWH interfere at multiple levels with the inflammatory cascade (Figure 1). The effects depend on the dose, timing, the clinical setting and many unknown factors, leading to unpredictable effects.

\section{Heparin-induced thrombocytopenia}

A feared side effect of heparins is the development of heparin-induced thrombocytopenia, related to the binding of heparin to platelet factor 4 released from activated platelets. Some patients develop antibodies against this heparin-platelet factor 4 complex. The antibody-platelet factor 4-heparin complex subsequently binds to platelets, inducing platelet activation, aggregation and activation of the coagulation pathways. This sequence results in a loss of circulating platelets and a prothrombotic state [30]. Depending on the dose and type of heparin, on the population and on the criteria used for diagnosis, $<1$ to $5 \%$ of heparin-treated patients develop heparin-induced thrombocytopenia [31-33].

\section{Citrate}

Given the above concerns with heparin, why is regional citrate anticoagulation not the standard of care? For several reasons, physicians are reluctant to switch to citrate anticoagulation. These reasons include concerns that the use of citrate is complex, carries a high risk of metabolic derangement, might even be dangerous and is expensive. 


\section{Citrate: anticoagulant and buffer}

Citrate is both an anticoagulant and a buffer, and for this reason it can be difficult to use and understand. Sodium citrate, administered before the filter, chelates calcium. The associated regional hypocalcemia in the filter inhibits the generation of thrombin [34,35]. Citrate is partially removed by filtration or dialysis [36], and the remaining amount is rapidly metabolized in the citric acid (Krebs) cycle - especially in the liver, muscle and renal cortex while the chelated calcium is released and the lost calcium is replaced. Systemic coagulation is unaffected.

For anticoagulation, the citrate dose is adjusted to blood flow to attain an ionized calcium concentration $<0.4 \mathrm{mmol} / \mathrm{l}$ in the filter; the lower the calcium concentration, the higher the degree of anticoagulation. Some protocols use a fixed dose of citrate in relation to blood flow according to an algorithm, and target such doses at about $3 \mathrm{mmol}$ citrate/l blood flow [37]. Other protocols measure postfilter ionized calcium and adjust the citrate dose, which complicates the intervention but optimizes anticoagulation $[13,38]$.

While the anticoagulant strength of the citrate solution depends on the citrate concentration, the buffer strength depends on the proportion of strong cations in the fluid counterbalancing the citrate anion. One micromole of trisodium citrate provides the same buffer as $3 \mathrm{mmol}$ sodium bicarbonate, assuming the citrate is completely metabolized. In some solutions, however, hydrogen is used instead of sodium for some of the cation. Hydrogen (citric acid) does not act as a buffer. For example, in the ACD-A solution (citrate dextose) that is used in many protocols, $30 \%$ of the cations consist of hydrogen. The buffering capability of this solution is thus lower than when a pure trisodium citrate solution is used. In our view, the Stuart concept of acid-base provides an easier way to understand the buffering effect of citrate for those familiar with the concepts. After metabolism of citrate, the remaining sodium increases the strong ion difference (SID) $[39,40]:$

$$
\mathrm{SID}=\left(\mathrm{Na}^{+}+\mathrm{K}^{+}+\mathrm{Ca}^{2+}+\mathrm{Mg}^{2+}\right)-\left(\mathrm{Cl}^{-}+\text {lactate }{ }^{-}\right)
$$

An increased SID produces alkalosis, while the infusion of a zero-SID fluid decreases SID and causes acidosis. Citrate is a triprotic acid with $\mathrm{pK}_{\mathrm{a}}$ values of 3.13, 4.76 and 6.40. A sodium citrate solution thus has a SID of zero until the citrate is metabolized. In conditions where citrate metabolism is grossly impaired, therefore, even trisodium citrate can first cause some acidosis before it produces its alkalinizing effect.

Because sodium citrate acts as buffer, the replacement fluids must be adjusted accordingly. A myriad of homemade systems are in use and, unfortunately, add to confusion among clinicians: for predilution or postdilution, for hemodialysis or hemofiltration, or for their combination. All these modalities use different fluids and different ways to attain metabolic stability. None of the systems has yet proven superiority. The pros and cons have been summarized in various reviews [38].

\section{Metabolic consequences, tolerance and limitations}

Reported derangements include metabolic alkalosis and acidosis, hypernatremia and hyponatremia, and hypocalcemia. They are detected with proper monitoring and the local protocol should describe how to adjust flows under different conditions to prevent such problems. The incidence of metabolic complications depends on the amount of citrate administered, the design, rules and flexibility of the protocol, and its proper use. In the largest randomized controlled trial, metabolic control with citrate was better than with heparin [35].

\section{Calcium}

Citrate tolerance depends on the amount of citrate entering the body and the capacity to metabolize citrate. The amount of citrate needed for anticoagulation is lower when using continuous hemodialysis compared with hemofiltration, because dialysis can be performed at a lower blood flow and therefore requires a lower citrate dose. Citrate metabolism is diminished in case of liver failure and also of poor tissue perfusion [41,42], because the Krebs cycle only operates under aerobic conditions. Citrate accumulates if its metabolism is insufficient. The citrate molecule is not toxic in itself, but citrate accumulation causes ionized hypocalcemia in the systemic circulation, which may decrease cardiac contractility, cause hypotension by decreasing vascular tone and contribute to systemic hypocoagulability. Monitoring of the patient's ionized calcium is therefore crucial. Ionized hypocalcemia is the most sensitive indicator of citrate accumulation, but it can also stem from other causes, including an insufficient replacement rate. Citrate accumulation, while decreasing ionized calcium, concomitantly increases the total calcium concentration, because the citrate-bound calcium increases and calcium is replaced. The total to ionized calcium ratio, therefore, is a useful test to detect citrate accumulation [43-45]. A rise in total to ionized calcium ratio above 2.25 should trigger consideration of probable citrate accumulation [43]. Although citrate accumulation can also increase the anion gap, this variable is insensitive in critically ill patients. In the aforementioned randomized trial, citrate anticoagulation was better tolerated than heparin [37].

\section{Metabolic alkalosis or acidosis}

Notably, accumulation of citrate can additionally lead to acid-base derangements. Metabolic alkalosis occurs if a 
high sodium citrate load (for example, protocol violation or accidentally rapid infusion) is delivered and when the citrate is appropriately metabolized, providing bicarbonate equivalents or, according to the Stewart concept, leaving unopposed sodium (see above) [38]. Metabolic acidosis occurs if a large citrate dose is not metabolized; for example, in liver failure or poor peripheral perfusion. A high lactate level (for example, $>5 \mathrm{mmol} / \mathrm{l}$ ) in patients with liver failure before the start of citrate CRRT may act as a useful marker of greater risk for citrate accumulation. Septic patients with a high lactate level generally tolerate citrate remarkably well if circulation improves. Accumulation of citrate is easily detectable with standard monitoring: arterial blood gases, ionized and total calcium at 6-hour intervals. If citrate accumulation occurs together with metabolic acidosis and an increasing calcium ratio, the citrate dose should be decreased or discontinued, calcium replaced and the patient should receive bicarbonate replacement, preferably as part of the balanced replacement fluids [38]. With proper monitoring, citrate accumulation causes no clinical symptoms.

\section{Inflammation}

Apart from the potentially proinflammatory effects of heparin on the release of mediators from leukocytes and platelets (see above), it may be hypothesized that local hypocalcemia at a membrane level during anticoagulation with citrate might reduce inflammatory mediator release from cells adhered to the membrane [46,47]. Activation of neutrophils and the release of mediators from intracellular granules are preceded by transient increases in cytosolic $\mathrm{Ca}^{2+}$ caused by the mobilization of $\mathrm{Ca}^{2+}$ from intracellular stores followed by the influx of $\mathrm{Ca}^{2+}$ into the cell through the plasma membrane channels. Cytosolic $\mathrm{Ca}^{2+}$ subsequently acts as an intracellular messenger [48-50]. It should be noted that the effects of citrate on complement activation, especially seen when using the old unsubstituted cuprophane membranes, are not uniform - some studies report no effect [51-53], others report a suppression of activation [46]. Degranulation seems to be mediated by a different membrane receptor, not related to complement activation and neutropenia [54].

\section{Energy and mitochondria}

Citrate $\left(\mathrm{C}_{6} \mathrm{H}_{5} \mathrm{O}_{7}\right)$ is a source of energy, conferring $3 \mathrm{kcal} / \mathrm{g}$ $(0.59 \mathrm{kcal} / \mathrm{mmol})[55,56]$. One gram of citrate corresponds to about $5 \mathrm{mmol}$. Part of the citrate administered before the filter enters the patient's circulation. The amount depends on the citrate infusion dose, its concentration in the filter and the amount removed by filtration or dialysis. The latter can be estimated, because the sieving coefficient of citrate is close to 1.0. Effluent loss corresponds to effluent flow $\times$ citrate concentration in the filter. The citrate concentration in the filter can be estimated by dividing the administered amount by blood flow. Postdilution hemofiltration estimation is easiest the amount lost by filtration equals the infusion rate $x$ filtration fraction, and the amount entering the patient is equivalent to the infusion rate $\times(1-$ filtration fraction $)$. Assuming a blood flow of $200 \mathrm{ml} /$ minute, a citrate infusion rate of $3 \mathrm{mmol} / \mathrm{l}$ blood flow ( $36 \mathrm{mmol} /$ hour), a filtration fraction of 0.20 , and a filter running $80 \%$ of the time, about $553 \mathrm{mmol}$ citrate enter the patient's circulation per day, providing close to $333 \mathrm{kcal} /$ day. The present calculation is an estimate, based on physiological principles. Actual measurements have been published in abstract form recently [57].

Note that citrate, although being an energy source, does not need insulin to enter the cell. Citrate is an easy fuel for the mitochondria, and may replenish the Krebs cycle if intermediates are scarce. Substrate availability is a crucial regulator of the Krebs cycle. The cycle is a central pathway providing energy and maintaining the mitochondrial redox state. In sepsis, inhibition of pyruvate dehydrogenase limits pyruvate conversion to acetylcoenzyme A, the main substrate of the cycle [58]. Furthermore, Weinberg and colleagues have shown that citric acid cycle intermediates may protect proximal tubules against injury and may promote recovery from sustained mitochondrial energetic deficit. This deficit occurs after hypoxia and reperfusion and acts by lowering the cellular burden of non-esterified fatty acids that appear to account for much of the continuing mitochondrial dysfunction $[59,60]$. The serum concentrations of citrate reached during CRRT with citrate as an anticoagulant (0.3 to $0.5 \mathrm{mmol} / \mathrm{l}$ ) [44] are in the range expected to modify tubular cell metabolism (personal communication).

\section{Life-threatening adverse event}

The main risk of citrate anticoagulation consists of the uncontrolled systemic infusion of a hypertonic citrate solution causing acute and severe hypocalcemia, hypotension and possibly cardiac arrest. Treatment consists of immediate calcium infusion and discontinuation of citrate infusion.

\section{Costs}

Although comparative studies are not available and expenses differ between modalities, estimated costs of citrate anticoagulation are not substantially higher than those associated with heparin anticoagulation. Instead of measuring the activated partial thromboplastin time for the control of heparin anticoagulation, systemic ionized calcium and once-daily measurement of total calcium is sufficient for the monitoring citrate accumulation, with more frequent measurement only in patients at risk of 
Table 1. Randomized clinical studies comparing citrate with heparin anticoagulation for CRRT

\begin{tabular}{|c|c|c|c|c|c|c|c|c|c|}
\hline \multirow[b]{2}{*}{ Reference } & \multirow[b]{2}{*}{ Design } & \multicolumn{2}{|c|}{ Circuit life (hours) $^{\mathrm{a}}$} & \multicolumn{2}{|c|}{ Bleeding } & \multicolumn{2}{|c|}{ Transfusion (RBC/day $\left.{ }^{b}\right)$} & \multicolumn{2}{|c|}{ Survival } \\
\hline & & Citrate & Heparin & Citrate & Heparin & Citrate & Heparin & Citrate & Heparin \\
\hline $\begin{array}{l}\text { Monchi and } \\
\text { colleagues [63] }\end{array}$ & $\begin{array}{l}\text { RCOT, } \\
n=20\end{array}$ & $\begin{array}{c}70 \\
(44 \text { to } 140), \\
P<0.001\end{array}$ & $\begin{array}{c}40 \\
\text { (17 to 48) }\end{array}$ & $n=0$ & $n=1$ & $\begin{array}{c}0.2 \\
(0 \text { to } 0.4) \\
P<0.001\end{array}$ & $\begin{array}{c}1.0 \\
\text { (0 to } 2.0)\end{array}$ & & \\
\hline $\begin{array}{l}\text { Kutsogiannis and } \\
\text { colleagues [64] }\end{array}$ & $\begin{array}{l}\text { RCT, } \\
n=30\end{array}$ & $\begin{array}{c}125 \\
(95 \text { to } 157) \\
P<0.001\end{array}$ & $\begin{array}{c}38 \\
\text { (25 to 62) }\end{array}$ & $\begin{array}{c}\text { RR } 0.17 \\
(0.03 \text { to } 1.04) \\
P=0.06\end{array}$ & & $\begin{array}{c}0.53 \\
(0.24 \text { to } 1.20) \\
P=0.13\end{array}$ & & & \\
\hline $\begin{array}{l}\text { Betjes and } \\
\text { colleagues [65] }\end{array}$ & $\begin{array}{c}\text { RCT } \\
n=48\end{array}$ & & & $\begin{array}{c}0 \% \\
P<0.01\end{array}$ & $33 \%$ & $\begin{array}{c}0.43 \\
P=0.01\end{array}$ & 0.88 & & \\
\hline $\begin{array}{l}\text { Oudemans-Van } \\
\text { Straaten and } \\
\text { colleagues [35] }\end{array}$ & $\begin{array}{c}\mathrm{RCT}^{\mathrm{c}} \\
n=200\end{array}$ & $\begin{array}{c}27 \\
(13 \text { to } 47) \\
\text { NS }\end{array}$ & $\begin{array}{c}26 \\
(15 \text { to } 43)\end{array}$ & $\begin{array}{c}6 \% \\
P=0.08\end{array}$ & $16 \%$ & $\begin{array}{c}0.27 \\
\text { (0 to } 0.63) \\
P=0.31\end{array}$ & $\begin{array}{c}0.36 \\
\text { (0 to } 0.83)\end{array}$ & $\begin{array}{c}52 \%{ }^{d} \\
P=0.03\end{array}$ & $37 \%^{d}$ \\
\hline $\begin{array}{l}\text { Hetzel and } \\
\text { colleagues [66] }\end{array}$ & $\begin{array}{c}\text { RCT } \\
n=170\end{array}$ & $\begin{array}{c}37.5 \pm 23 \\
P<0.001\end{array}$ & $26.1 \pm 19.2$ & $\begin{array}{c}14.5 \% \\
P=0.06\end{array}$ & $5.7 \%$ & & & $\begin{array}{c} \pm 30 \% \text { e } \\
\text { NS }\end{array}$ & $\pm 43 \%$ e \\
\hline
\end{tabular}

CRRT, continuous renal replacement therapy; RCOT, randomized cross-over trial; RCT, randomized controlled trial; NS, not significant; RR, relative risk. ${ }^{a}$ Median (interquartile range). ${ }^{b}$ Number of red cell units per day of continuous venovenous hemofiltration. 'Comparing citrate with the low molecular weight heparin nadroparin. ${ }^{\mathrm{d}}$ Three-month survival on an intention-to-treat analysis. ${ }^{\mathrm{e}}$ Thirty-day mortality, estimated from the Kaplan-Meier curve.

accumulation. Replacement fluids including intravenous calcium are slightly more expensive when citrate is used. If the costs of less bleeding and longer circuit life are calculated, costs with citrate are probably less or may in fact represent cost savings.

\section{Strategies to increase the safety of citrate}

The use of citrate offers many advantages to the patient, which can only be taken if the risks are well controlled. The incidence of metabolic complications largely depends on the design, rules and flexibility of the protocol, and its proper use. Safe introduction of citrate should start with the choice of a well-designed and flexible protocol with proven efficacy and adjusted to the local preferences of modality and dose, and availability of fluids and devices. Results of ionized calcium measurement should be available 24 hours a day. Implementation of the protocol includes the training of staff to create understanding and awareness of acid-base and calcium monitoring, and the correction of imbalance [38]. Safety is further improved by the incorporation of a citrate module in the CRRT device, blocking persistent citrate infusion if the blood pump stops. Pop-ups in the patient data management system and computerized algorithms may add to patient safety.

\section{Heparin versus citrate: randomized controlled trials}

\section{Efficacy and side effects}

The primary goal of anticoagulation for CRRT is to extend circuit life. Indeed, a shorter circuit life may result in underdosing of CRRT. Several studies have compared circuit life and bleeding complications under citrate treatment with nonrandomized controls on heparin treatment (summarized in $[13,38]$ ). Groups were often not comparable, because the patients receiving citrate generally had a higher bleeding risk. Nevertheless, bleeding complications were lower in patients receiving citrate [61,62]. Circuit survival with citrate was usually longer, sometimes similar and, in some studies, shorter than with heparin (summarized in [38]). Five randomized controlled studies comparing anticoagulation with citrate to anticoagulation with heparin have been published [63-66] (Table 1). Three of these studies report a significantly longer circuit survival with citrate, four studies (a trend to) less bleeding, and two studies less red blood cell transfusion using citrate.

\section{Clinical outcomes}

Most randomized studies evaluating heparin anticoagulation for CRRT are too small for a robust evaluation of clinical outcome [13]. A recent randomized study in 200 critically ill patients receiving CRRT for acute kidney injury, comparing anticoagulation with LMWH (nadroparin) to regional anticoagulation with citrate, unexpectedly showed a 15\% absolute increase in 3-month survival using an intention-to-treat analysis [35] (Table 2). In addition to improved patient survival, kidney survival was also better with citrate. The difference was significant for all per-protocol patients and tended to significance for the surviving patients. Among the higher proportion of surviving patients, therefore, more patients were free from chronic dialysis in the citrate group. Of note, the benefit of citrate on survival could not be fully explained by less bleeding. Citrate appeared particularly beneficial in surgical patients, younger patients, patients with sepsis (compared with no sepsis) and in patients with a high degree of organ failure. In none of the subgroups did citrate perform worse than heparin. These findings suggest the need for a better understanding of citrate 
Table 2. Advantages and disadvantages of heparin or citrate anticoagulation during continuous renal replacement therapy

\begin{tabular}{|c|c|c|}
\hline & Heparins & Citrate \\
\hline \multicolumn{3}{|l|}{ Clinical } \\
\hline Anticoagulation & Regional and systemic & Regional, not systemic \\
\hline Risk of bleeding & Higher & Not increased \\
\hline Circuit life & Similar or shorter & Similar or longer \\
\hline Metabolic control & Good & Good if well performed \\
\hline Metabolic derangements & & Greater risk if not well controlled \\
\hline Understanding & Easy & Difficult \\
\hline \multirow[t]{2}{*}{ Life-threatening complications } & Massive bleeding & \\
\hline & Heparin-induced thrombocytopenia (UFH > LMWH) & Cardiac arrest due to unintended rapid infusion \\
\hline Clinical outcome & & Possibly better patient and kidney survival \\
\hline \multicolumn{3}{|l|}{ Biochemical } \\
\hline \multirow[t]{3}{*}{ Anticoagulation } & Critically ill patients exhibit heparin resistance due to: & \\
\hline & - Low antithrombin (high consumption and degradation) & \\
\hline & $\begin{array}{l}\text { - Acute phase proteins and apoptotic/necrotic cells bind } \\
\text { heparin (UFH >LMWH) }\end{array}$ & \\
\hline \multirow[t]{4}{*}{ Proinflammatory effects } & $\begin{array}{l}\text { Inhibit the anti-inflammatory properties of antithrombin } \\
\text { (UFH >LMWH) }\end{array}$ & \\
\hline & Trigger antithrombin degradation by elastase & \\
\hline & $\begin{array}{l}\text { Release myeloperoxidase, elastase, platelet factor 4, } \\
\text { superoxide dismutase into the circulation (UFH, LMWH) }\end{array}$ & \\
\hline & $\begin{array}{l}\text { Increase in lipopolysaccharide-induced, LPB-dependent } \\
\text { IL-8 and IL-1 } \beta \text { secretion from monocytes (LMWH, UFH) }\end{array}$ & \\
\hline \multirow[t]{3}{*}{ Anti-inflammatory effects } & Inhibit thrombin generation (UFH, LMWH) & $\begin{array}{l}\text { Its use prevents the release of granular products from } \\
\text { neutrophils and platelets }\end{array}$ \\
\hline & $\begin{array}{l}\text { Block P-selectin and L selectin-mediated cell adhesion } \\
\text { (UFH, LMWH) }\end{array}$ & \\
\hline & Decrease cytokine generation in vitro, not in vivo & \\
\hline Phagocytosis & $\begin{array}{l}\text { Bind to apoptotic and necrotic cells and may delay } \\
\text { phagocytic clearance (UFH }>\text { LMWH) }\end{array}$ & \\
\hline \multirow[t]{2}{*}{ Bio-energetic properties } & & $\begin{array}{l}\text { Provides energy without needing insulin for entrance into } \\
\text { the cell }\end{array}$ \\
\hline & & May protect against mitochondrial dysfunction \\
\hline
\end{tabular}

UFH, unfractionated heparin; LMWH, low molecular weight heparin; LBP, lipopolysaccharide-binding protein.

anticoagulation and its challenges. These findings, however, were not confirmed in a more recent multicenter randomized trial, including a slightly different patient population, using a different citrate protocol and reporting a shorter follow-up [66].

\section{Conclusion}

The use of heparin as an anticoagulant for CRRT is hampered by complex interactions between the drug and numerous acute phase proteins, and apoptotic and necrotic cells. In addition, heparin binding inhibits the anti-inflammatory effects of AT, which may already be low, and triggers the release of inflammatory mediators from blood and endothelial cells. This myriad of actions leads to an unpredictable dose-effect relationship and an uncontrollable and potentially deleterious interference with proinflammatory and anti-inflammatory pathways. In randomized clinical trials, heparins are often less effective for preserving circuit life while they increase the patient's risk of bleeding. The benefits of citrate include less bleeding, a longer or similar circuit life, and possibly better patient and kidney survival. The last benefit needs to be confirmed in larger randomized controlled multicenter trials. The use of citrate might be associated with less inflammation and has useful bio-energetic implications. These observations call into question the primacy of heparins for circuit anticoagulation in the critically ill patient and suggest a greater role for citrate (Table 2). 
This article is part of the series Renal replacement therapy, edited by John Kellum and Lui Forni.

The full advantage of citrate anticoagulation can only be realized, however, if its risks are well controlled by means of a sound protocol, well-trained staff, and the incorporation of a citrate module in the CRRT device.

\section{Abbreviations}

AT, antithrombin; CRRT, continuous renal replacement therapy; IL, interleukin; LMWH, low molecular weight heparin; NF, nuclear factor; SID, strong ion difference; TNF, tumor necrosis factor.

\section{Competing interests}

The authors declare that they have no competing interests.

\section{Author details}

'Department of Intensive Care Medicine, Onze Lieve Vrouwe Gasthuis, Oosterpark 9, 1091 AC Amsterdam, The Netherlands. ${ }^{2}$ Department of Critical Care Medicine, University of Pittsburgh, 3550 Terrace Street, Pittsburgh, PA 15213, USA. 'Department of Intensive Care, Austin Hospital, 145 Studley Road, Heidelberg, Victoria 3084, Australia.

Published: 25 January 2011

\section{References}

1. Uchino S, Bellomo R, Morimatsu H, Morgera S, Schetz M, Tan I, Bouman C, Macedo E, Gibney N, Tolwani A, Oudemans-van Straaten H, Ronco C, Kellum $J A$ : Continuous renal replacement therapy: a worldwide practice survey. The beginning and ending supportive therapy for the kidney (B.E.S.T. kidney) investigators. Intensive Care Med 2007, 33:1563-1570.

2. Hirsh J, Warkentin TE, Shaughnessy SG, Anand SS, Halperin JL, Raschke R, Granger C, Ohman EM, Dalen JE: Heparin and low-molecular-weight heparin: mechanisms of action, pharmacokinetics, dosing, monitoring, efficacy, and safety. Chest 2001, 119:64S-94S

3. Cohen JR, Sarfati I, Birnbaum E, Benacquista T, Wise L: The inactivation of antithrombin III by serum elastase in patients with surgical infections. Am Surg 1990, 56:665-667

4. Jordan RE, Nelson RM, Kilpatrick J, Newgren JO, Esmon PC, Fournel MA Antithrombin inactivation by neutrophil elastase requires heparin. Am J Med 1989, 87:195-22S

5. Manson L, Weitz Jl, Podor TJ, Hirsh J, Young E: The variable anticoagulant response to unfractionated heparin in vivo reflects binding to plasma proteins rather than clearance. J Lab Clin Med 1997, 130:649-655.

6. Liu S, Hoke D, Julian J, Carson DD: Heparin/heparan sulfate (HP/HS) interacting protein (HIP) supports cell attachment and selective, high affinity binding of HP/HS. J Biol Chem 1997, 272:25856-25862.

7. Young E, Podor TJ, Venner T, Hirsh J: Induction of the acute-phase reaction increases heparin-binding proteins in plasma. Arterioscler Thromb Vasc Biol 1997, 17:1568-1574

8. Cosmi B, Fredenburgh JC, Rischke J, Hirsh J, Young E, Weitz Jl: Effect of nonspecific binding to plasma proteins on the antithrombin activities of unfractionated heparin, low-molecular-weight heparin, and dermatan sulfate. Circulation 1997, 95:118-124.

9. Hochart H, Jenkins PV, Preston RJ, Smith OP, White B, O'Donnell J: Concentration-dependent roles for heparin in modifying lipopolysaccharide-induced activation of mononuclear cells in whole blood. Thromb Haemost 2008, 99:570-575.

10. Gebska MA, Titley I, Paterson HF, Morilla RM, Davies DC, Gruszka-Westwood AM, Kakkar W, Eccles S, Scully MF: High-affinity binding sites for heparin generated on leukocytes during apoptosis arise from nuclear structures segregated during cell death. Blood 2002, 99:2221-2227.

11. Oudemans-Van Straaten HM, van SM, Molenaar PJ, Wester JP, Leyte A: Hemostasis during low molecular weight heparin anticoagulation for continuous venovenous hemofiltration: a randomized cross-over trial comparing two hemofiltration rates. Crit Care 2009, 13:R193.

12. van de Wetering J, Westendorp RG, van der Hoeven JG, Stolk B, Feuth JD, Chang PC: Heparin use in continuous renal replacement procedures: the struggle between filter coagulation and patient hemorrhage. J Am Soc Nephrol 1996, 7:145-150.

13. Oudemans-Van Straaten HM, Wester JP, de Pont AC, Schetz MR: Anticoagulation strategies in continuous renal replacement therapy: can the choice be evidence based? Intensive Care Med 2006, 32:188-202.

14. Carr JA, Silverman N: The heparin-protamine interaction. A review. J Cardiovasc Surg (Torino) 1999, 40:659-666.

15. Warren BL, Eid A, Singer P, Pillay SS, Carl P, Novak I, Chalupa P. Atherstone A Penzes I, Kubler A, Knaub S, Keinecke HO, Heinrichs H, Schindel F, Juers M, Bone RC, Opal SM: Caring for the critically ill patient. High-dose antithrombin III in severe sepsis: a randomized controlled trial. JAMA 2001 286:1869-1878.

16. Leithauser B, Schumacher J, Lendemans S, Tillmanns H, Matthias FR: Antithrombin attenuates microvascular leakage and leukocyteendothelial interaction in response to endotoxin. Semin Thromb Hemost 2002, 28(Suppl 1):87-94.

17. Hoffmann JN, Vollmar B, Laschke MW, Inthorn D, Kaneider NC, Dunzendorfer S, Wiedermann CJ, Romisch J, Schildberg FW, Menger MD: Adverse effect of heparin on antithrombin action during endotoxemia: microhemodynamic and cellular mechanisms. Thromb Haemost 2002, 88:242-252.

18. Heinzelmann M, Bosshart H: Heparin binds to lipopolysaccharide (LPS)binding protein, facilitates the transfer of LPS to CD14, and enhances LPS-induced activation of peripheral blood monocytes. J Immuno/ 2005 174:2280-2287.

19. Borawski J: Myeloperoxidase as a marker of hemodialysis biocompatibility and oxidative stress: the underestimated modifying effects of heparin. Am J Kidney Dis 2006, 47:37-41.

20. Gritters M, Borgdorff P, Grooteman MP, Schoorl M, Schoorl M, Bartels PC, Tangelder GJ, Nube MJ: Platelet activation in clinical haemodialysis: LMWH as a major contributor to bio-incompatibility? Nephrol Dial Transplant 2008, 23:2911-2917.

21. Myrup B, Yokoyama H, Kristiansen OP, Ostergaard PB, Olivecrona T: Release of endothelium-associated proteins into blood by injection of heparin in normal subjects and in patients with type 1 diabetes. Diabet Med 2004, 21:1135-1140

22. Tasaki H, Yamashita K, Tsutsui M, Kamezaki F, Kubara T, Tanaka S, Sasaguri Y, Adachi T, Nakashima Y: Heparin-released extracellular superoxide dismutase is reduced in patients with coronary artery atherosclerosis. Atherosclerosis 2006, 187:131-138.

23. Cornet AD, Smit EG, Beishuizen A, Groeneveld AB: The role of heparin and allied compounds in the treatment of sepsis. Thromb Haemost 2007 98:579-586.

24. Levi M, van der Poll T: Inflammation and coagulation. Crit Care Med 2010, 38:S26-S34.

25. Black SC, Gralinski MR, Friedrichs GS, Kilgore KS, Driscoll EM, Lucchesi BR: Cardioprotective effects of heparin or $\mathrm{N}$-acetylheparin in an in vivo model of myocardial ischaemic and reperfusion injury. Cardiovasc Res 1995, 29:629-636.

26. Wang L, Brown JR, Varki A, Esko JD: Heparin's anti-inflammatory effects require glucosamine 6-O-sulfation and are mediated by blockade of $\mathrm{L}$ and P-selectins. J Clin Invest 2002, 110:127-136.

27. Thourani VH, Brar SS, Kennedy TP, Thornton LR, Watts JA, Ronson RS, Zhao ZQ, Sturrock AL, Hoidal JR, Vinten-Johansen J: Nonanticoagulant heparin inhibits NF-KB activation and attenuates myocardial reperfusion injury. Am J Physiol Heart Circ Physiol 2000, 278:H2084-H2093.

28. Hoffmann JN, Hartl WH, Faist E, Jochum M, Inthorn D: Tumor necrosis factor measurement and use of different anticoagulants: possible interference in plasma samples and supernatants from endotoxin-stimulated monocytes. Inflamm Res 1997, 46:342-347

29. Leitienne P, Fouque D, Rigal D, Adeleine P, Trzeciak MC, Laville M: Heparins and blood polymorphonuclear stimulation in haemodialysis: an expansion of the biocompatibility concept. Nephrol Dial Transplant 2000, 15:1631-1637

30. Warkentin TE: Heparin-induced thrombocytopenia: diagnosis and management. Circulation 2004, 110:e454-e458.

31. Verma AK, Levine M, Shalansky SJ, Carter CJ, Kelton JG: Frequency of heparin-induced thrombocytopenia in critical care patients. Pharmacotherapy 2003, 23:745-753.

32. Selleng K, Warkentin TE, Greinacher A: Heparin-induced thrombocytopenia in intensive care patients. Crit Care Med 2007, 35:1165-1176.

33. Selleng S, Selleng K, Wollert HG, Muellejans B, Lietz T, Warkentin TE, 
Greinacher A: Heparin-induced thrombocytopenia in patients requiring prolonged intensive care unit treatment after cardiopulmonary bypass. J Thromb Haemost 2008, 6:428-435.

34. Oudemans-Van Straaten HM: Anticoagulation for renal replacement therapy: heparin or citrate. In Controversies in Intensive Care Medicine. Edited by Kuhlen R, Moreno R, Ranieri M, Rhodes A. Berlin: Medizinische Wissenschaftliche Verlagsgesellschaft; 2008:153-161.

35. Oudemans-Van Straaten HM, Bosman RJ, Koopmans M, van der Voort PH, Wester JP, van der Spoel JI Dijksman LM, Zandstra DF: Citrate anticoagulation for continuous venovenous hemofiltration. Crit Care Med 2009, 37:545-552.

36. Swartz R, Pasko D, O'Toole J, Starmann B: Improving the delivery of continuous renal replacement therapy using regional citrate anticoagulation. Clin Nephrol 2004, 61:134-143.

37. Oudemans-Van Straaten HM: Citrate anticoagulation for continuous renal replacement therapy in the critically ill. Blood Purification 2010, 29:208-213

38. Joannidis M, Oudemans-Van Straaten HM: Clinical review: Patency of the circuit in continuous renal replacement therapy. Crit Care 2007, 11:218.

39. Morgan TJ: The Stewart approach - one clinician's perspective. Clin Biochem Rev 2009, 30:41-54.

40. Egi M, Naka T, Bellomo R, Cole L, French C, Trethewy C, Wan L. Langenberg CC, Fealy N, Baldwin I: A comparison of two citrate anticoagulation regimens for continuous veno-venous hemofiltration. Int J Artif Organs 2005, 28:1211-1218

41. Apsner R, Schwarzenhofer M, Derfler K, Zauner C, Ratheiser K, Kranz A: Impairment of citrate metabolism in acute hepatic failure. Wien Klin Wochenschr 1997, 109:123-127.

42. Kramer L, Bauer E, Joukhadar C, Strobl W, Gendo A, Madl C, Gangl A: Citrate pharmacokinetics and metabolism in cirrhotic and noncirrhotic critically ill patients. Crit Care Med 2003, 31:2450-2455.

43. Meier-Kriesche HU, Gitomer J, Finkel K, DuBose T: Increased total to ionized calcium ratio during continuous venovenous hemodialysis with regional citrate anticoagulation. Crit Care Med 2001, 29:748-752.

44. Bakker AJ, Boerma EC, Keidel H, Kingma P, van der Voort PH: Detection of citrate overdose in critically ill patients on citrate-anticoagulated venovenous haemofiltration: use of ionised and total/ionised calcium. Clin Chem Lab Med 2006, 44:962-966.

45. Hetzel GR, Taskaya G, Sucker C, Hennersdorf M, Grabensee B, Schmitz M: Citrate plasma levels in patients under regional anticoagulation in continuous venovenous hemofiltration. Am J Kidney Dis 2006, 48:806-811.

46. Bohler J, Schollmeyer P, Dressel B, Dobos G, Horl WH: Reduction of granulocyte activation during hemodialysis with regional citrate anticoagulation: dissociation of complement activation and neutropenia from neutrophil degranulation. J Am Soc Nephrol 1996, 7:234-241.

47. Bohler J, Donauer J, Birmelin M, Schollmeyer PJ, Horl WH: Mediators of complement-independent granulocyte activation during haemodialysis: role of calcium, prostaglandins and leukotrienes. Nephrol Dial Transplant 1993, 8:1359-1365.

48. Andersson T, Dahlgren C, Pozzan T, Stendahl O, Lew PD: Characterization of fMet-Leu-Phe receptor-mediated $\mathrm{Ca}^{2+}$ influx across the plasma membrane of human neutrophils. Mol Pharmacol 1986, 30:437-443.

49. Lew PD, Wollheim CB, Waldvogel FA, Pozzan T: Modulation of cytosolic-free calcium transients by changes in intracellular calcium-buffering capacity: correlation with exocytosis and $\mathrm{O}_{2}$-production in human neutrophils. J Cell Biol 1984, 99:1212-1220.

50. Haag-Weber M, Mai B, Deppisch R, Gohl H, Horl WH: Studies of biocompatibility of different dialyzer membranes: role of complement system, intracellular calcium and inositol-triphosphate. Clin Nephrol 1994, 41:245-251.

51. Dhondt A, Vanholder R, Tielemans C, Glorieux G, Waterloos MA, De Smet R, Lameire N: Effect of regional citrate anticoagulation on leukopenia, complement activation, and expression of leukocyte surface molecules during hemodialysis with unmodified cellulose membranes. Nephron 2000, 85:334-342.

52. Gabutti L, Ferrari N, Mombelli G, Keller F, Marone C: The favorable effect of regional citrate anticoagulation on interleukin- $1 \beta$ release is dissociated from both coagulation and complement activation. J Nephrol 2004, 17:819-825.

53. Polanska K, Opatrny K, Jr, Rokyta R, Jr, Krouzecky A, Vit L, Kasal E: Effect of regional citrate anticoagulation on thrombogenicity and biocompatibility during CVVHDF. Ren Fail 2006, 28:107-118.

54. Bos JC, Grooteman MP, van Houte AJ, Schoorl M, van Limbeek J, Nube MJ: Low polymorphonuclear cell degranulation during citrate anticoagulation: a comparison between citrate and heparin dialysis. Nephrol Dial Transplant 1997, 12:1387-1393.

55. Food energy - methods of analysis and conversion factors. FAO Food and Nutrition Paper 77 [ftp://ftp.fao.org/docrep/fao/006/y5022e/y5022e00.pdf]

56. Citric acid [www.ecama.org/level_2/SDS/1CAM22April1998.doc]

57. Balik M, Zakharchenko M, Otahal M, Hruby J, Rusinova K, Polak F, Stach Z, Vavrova J, Jabor A: Quantification of systemic dose of substrates for intermediate metabolism during citrate anticoagulation of continous renal replacement therapy. Intensive Care Med 2010, 36:S293.

58. Vary TC, Hazen SA, Maish G, Cooney RN: TNF binding protein prevents hyperlactatemia and inactivation of PDH complex in skeletal muscle during sepsis. J Surg Res 1998, 80:44-51.

59. Weinberg JM, Venkatachalam MA, Roeser NF, Nissim I: Mitochondrial dysfunction during hypoxia/reoxygenation and its correction by anaerobic metabolism of citric acid cycle intermediates. Proc Natl Acad Sci USA 2000, 97:2826-2831.

60. Feldkamp T, Weinberg JM, Horbelt M, Von Kropff C, Witzke O, Nurnberger J, Kribben A: Evidence for involvement of nonesterified fatty acid-induced protonophoric uncoupling during mitochondrial dysfunction caused by hypoxia and reoxygenation. Nephrol Dial Transplant 2009, 24:43-51.

61. Ward DM, Mehta RL: Extracorporeal management of acute renal failure patients at high risk of bleeding. Kidney Int Supp/ 1993, 41:S237-S244.

62. van der Voort PH, Postma SR, Kingma WP, Boerma EC, Van Roon EN: Safety of citrate based hemofiltration in critically ill patients at high risk for bleeding: a comparison with nadroparin. Int J Artif Organs 2006, 29:559-563.

63. Monchi M, Berghmans D, Ledoux D, Canivet UL, Dubois B, Damas P: Citrate vs. heparin for anticoagulation in continuous venovenous hemofiltration: a prospective randomized study. Intensive Care Med 2004, 30:260-265.

64. Kutsogiannis DJ, Gibney RT, Stollery D, Gao J: Regional citrate versus systemic heparin anticoagulation for continuous renal replacement in critically ill patients. Kidney Int 2005, 67:2361-2367.

65. Betjes MG, van Oosterom D, van Agteren M, van de WJ: Regional citrate versus heparin anticoagulation during venovenous hemofiltration in patients at low risk for bleeding: similar hemofilter survival but significantly less bleeding. J Nephrol 2007, 20:602-608.

66. Hetzel GR, Schmitz M, Wissing H, Ries W, Schott G, Heering PJ, Isgro F, Kribben A, Himmele R, Grabensee B, Rump LC: Regional citrate versus systemic heparin for anticoagulation in critically ill patients on continuous venovenous haemofiltration: a prospective randomized multicentre trial. Nephrol Dial Transplant 2010, 26:232-239.

\section{doi:10.1186/cc9358}

Cite this article as: Oudemans-van Straaten, et al: Clinical review: Anticoagulation for continuous renal replacement therapy - heparin or citrate? Critical Care 2011, 15:202 